\title{
' IDENTIFICAÇÃO DE TIPOLOGIA DOCUMENTAL COMO METODOLOGIA PARA ORGANIZAÇÃO DE ARQUIVOS DE ARQUITETURA
}

\author{
Kallyne Kelly Rodrigues Vila Flor \\ Graduada em Arquivologia \\ kallynevilaflor@gmail.com
}

\section{Resumo}

\begin{abstract}
Este trabalho de pesquisa tem o objetivo de apresentar as particularidades que ocorrem na produção e tramitação dos documentos de arquitetura de forma a promover um conhecimento detalhado acerca dos processos de formação desse tipo de arquivos. Aborda a questão da gestão de documentos no que se refere à identificação dos tipos e espécie de documentos produção e tramitação em um escritório de arquitetura, compreendendo no contexto arquivístico - Arquivos Especiais e Especializados, bem como a apreciação dos órgãos de fiscalização e controle através das diretrizes, manuais, normas ou recomendações que direcionem o arquiteto e o arquivista no processo de organização dessa documentação. Trazendo como repercussão a demonstração do fluxograma existente entre os órgãos de controle/fiscalização e os escritórios de arquitetura, contemplando todas as etapas de produção e tramitação dos documentos de arquitetura no ambiente de escritório e fora dele. Assim, ao longo dessa pesquisa pudemos identificar a falta de um manual, diretriz ou normatização que direcione aos arquivistas e aos demais profissionais que lidam como esses tipos e espécies de documento como gerir esses arquivos.
\end{abstract}

Palavras-chave: Arquivos de Arquitetura. Arquivos Especializados e Especiais. Produção e tramitação documental.

\section{INTRODUÇÃO}

As tecnologias de informação são uma realidade dentro e fora das instituições arquivísticas, à cultura inclusiva de acesso a informação permite um aumento e ampliação da circulação da informação em grandes proporções o que provocou mudanças irreversíveis na teoria e prática de diversas áreas.

Constatamos que os arquitetos precisaram trocar a prancheta manual-artesanal pelo software, depois de identificarem a necessidade de se agregar muito mais agilidade e precisão ao processo de construção de sua arte: plantas e projetos. O mesmo ocorre com a Arquivologia, que tende a se adaptar às novas realidades tecnológicas que contribuem através de ferramentas contemporâneas de produção documental para o melhoramento das atividades que norteiam às práticas arquivísticas.

Diante da nossa decisão em evidenciar os arquivos de escritórios de arquitetura para encontrar elementos que entrelaçam a
Arquivologia e Arquitetura, não é tão inusitado quanto aparenta. A troca de experiências e possíveis contribuições aliadas à evolução dos modos de operação dessas áreas do conhecimento é que nos motiva em encontrarmos elos entre estas respectivas áreas.

A razão de se pesquisar tais arquivos, é poder examinar, compreender e apresentar a produção e tramitação dos documentos arquitetônicos dentro e fora do escritório, bem como evidenciar os caminhos percorridos por estes, buscando-se entender quais procedimentos, são utilizados para a realização. Logo, a compatibilidade da temática com o objeto de estudo avança, tendo em vista que, embora não sendo praticada, a Arquivologia está entrelaçada em todas as áreas, pois todo e qualquer empreendimento, escritório, instituição produz documentos. Considerando o valioso universo de possibilidades, ainda pouco explorado, associado à limitada literatura arquivística sobre a temática, juntamente com a vontade de evidenciar os arquivos de arquitetura, e torná- 
lo opção palpável para campo de pesquisa/trabalho na Arquivologia.

É importante destacar que os arquivos de arquitetura são um conjunto harmônico que refletem a atividade e a função de um produtor específico - o arquiteto. Isso significa, que os arquivos são produzidos organicamente, e que estes profissionais precisam buscar meios de geri-los adequadamente para poderem comprovar desde sua experiência profissional, autoria de produção, à responsabilidade técnica, portfólio, minimizar o retrabalho, sendo esse último, o maior problema, pois todo o processo precisa ser feito de maneira confiável, íntegra para que o objetivo final que é o projeto legal-executivo, seja aprovado pelos órgãos competentes ao ponto de alcançar a expectativa do cliente.

Nesse contexto, considerando o valioso universo de possibilidades, ainda pouco explorado, o trabalho foi realizado partindo da pouca e limitada literatura arquivística sobre o assunto. Associando a teoria com o conhecimento adquirido com a prática, descortinando, assim, os arquivos de arquitetura, e tornando os processos de sua concepção mais palpáveis no que tange a relação do arquiteto com a documentação que este produz. Diante dessa argumentação surgiu a seguinte indagação acerca desses arquivos especiais e especializados: Quais são os tipos/espécies documentais produzidos e tramitados entre um escritório de arquitetura e o poder público?

O objetivo geral deste documento é apresentar os aspectos de produção e tramitação dos documentos de um escritório de arquitetura. E como repercussão desse objetivo geral, são estabelecidos os seguintes objetivos específicos: Explicar os procedimentos da produção e da tramitação dos documentos arquitetônico do escritório Vila Flor Arquitetura junto a Prefeitura Municipal de João Pessoa; Identificar os processos de produção e tramitação dos documentos arquitetura; Demonstrar o fluxograma que existe entre os clientes, órgãos de controle e fiscalização e os escritórios de arquitetura.

Para conseguir alcançar os objetivos apoiamo-nos em uma metodologia de cunho exploratório qualitativo, construída da seguinte maneira: pesquisa bibliográfica; levantamento através da observação in loco dos dados e a identificação dos tipos/espécie documentais produzidos pelos arquitetos parceiros e colaboradores do escritório Vila Flor Arquitetura e análise dos dados.

Esse mergulho introdutório se faz necessário para que haja um maior entendimento da complexidade desta temática, uma vez que, um projeto arquitetônico é produzido conjuntamente entre $\mathrm{o}$ autor arquiteto e o co-autor cliente que procura um profissional para materializar um desejo, essa relação comercial e informacional precisa ser clara e juridicamente segura, pois se trata de uma relação comercial e como tal precisa garantir alguns direitos, essas ações são materializadas em documentos que precisam ser organizados, arquivados e armazenados de acordo com sua função dentro do processo de trabalho desenvolvido de acordo com cada atividade desenvolvida.

\section{GESTÃO DOCUMENTAL}

Através da gestão de documentos é possível identificar elementos indispensáveis para o gerenciamento de documentos de arquivos. De acordo com o Arquivo Nacional (2005, p. 100) "gestão de documentos é o conjunto de procedimentos e operações técnicas referentes à produção, tramitação, uso, avaliação e arquivamento de documentos em fase corrente e intermediaria, visando sua eliminação ou recolhimento". No entanto, neste trabalho foi enfatizada as duas primeiras fases da gestão documental: a produção e tramitação.

A gestão documental permite que o documento seja acompanhado em todas as fases do ciclo vital, desde sua produção até sua eliminação ou guarda permanente. Esses estágios são compreendidos por Bernardes e Dellatorre (2010, p. 10).

\footnotetext{
"como sendo as etapas de evolução nas três idades do documento que compreendem os arquivos correntes onde os documentos estão ligados aos fins primários de produção ou recebimento cumprindo suas funções administrativas; intermediários os documentos provenientes do arquivo corrente com pouca consultam aguardando o termino dos prazos legais para serem eliminados ou guardados permanentemente e permanente os documentos são preservados em razão de seu valor histórico, testemunhal, legal, probatório e científico-cultural, servindo permanentemente como fonte de pesquisa".
} 
Os documentos arquivísticos são dotados de características que os tonam únicos, pois carregam em sua essência informações únicas que precisam ser acompanhadas por uma política de gestão específica para esse tipo de arquivos, pois foram geradas a partir de uma atividade humana, e que são o testemunho de uma ação humana. Portanto, o desenvolvimento de uma política gestão documental é indispensável para que as instituições possam armazenar e conservar esse tipo de documentação.

A produção dos documentos arquitetônicos decorre das atividades rotineiras de um escritório de arquitetura, que geralmente acumulam em seus arquivos especializados documentos técnicos, gráficos e administrativos, esse talvez seja o que torna esses Arquivos tão interessantes de serem estudados, pois além das múltiplas espécies de documentos produzidos o valor do documento de arquitetura como fonte de prova só passa a ser concedido depois da edificação finalizada.

$\mathrm{O}$ grande desafio para o Arquivista nesse tipo de arquivo vem do trabalho nas instituições privados, onde em sua maioria não consegue realizar seu trabalho a tempo e alguns documentos acabam sem receber o tratamento adequado e, assim se dispersa. Um outro ponto é que nesses arquivos especializados privados o desenvolvimento de qualquer atividade arquivística fica a cargo de seu detento, haja vista que podemos dizer que além de Arquivos especiais e especializados esse são também Arquivos privados, ao contrário do que acontece nas instituições públicas onde as atividades podem ser realizadas de modo que atinjam os objetivos da gestão documental é o de acompanhar o documento em todas as fases do ciclo de vida dos mesmos.

A tramitação é uma parcela da gestão documental que vem se destacando nas últimas décadas. Essa notoriedade é uma consequência da forma de como nos comunicamos na contemporaneidade impulsionada pelo avanço tecnológico e velocidade na comunicação, manter o controle do fluxo informacional tornou-se cada vez mais um desafio. Os problemas causados pelas falhas de comunicação ou uma política de gestão ineficiente compromete o fluxo informacional, que nas organizações públicas ou privadas imprime prejuízo nas relações e nas atividades institucionais, desta forma a tramitação deve ser percebida e executada como parte de um plano sistemático da gestão documental.

\begin{abstract}
A ausência da política de gestão conduz a uma pluralidade, heterogeneidade e, por vezes, ausência de normas, métodos e procedimentos de trabalho nos serviços de protocolo e arquivo dos órgãos da administração pública, que vêm dificultando o acesso às informações, bem como provocando o acúmulo desordenado de documentos, transformando os arquivos em meros depósitos empoeirados de papéis. (BERNARDES; DELLATORRE, 2008, p. 5).
\end{abstract}

O principal objetivo da tramitação é manter sobre controle a documentação que circula na instituição, o registro no protocolo é o começo do trâmite. De acordo com Ferreira (2010, p.749) "trâmite seria o caminho ou atalho determinado". Desta forma, para que se possa manter o controle da produção até a destinação final do documento é preciso que o setor de protocolo mantenha uma relação estreita com o arquivo, o que torna os procedimentos arquivístico mais inteligível. Que Bernardes e Dellatorre (2008, p. 7) vão dizer que "as falhas no sistema de controle da tramitação comprometem a qualidade das atividades rotineiras, uma vez que dificulta o acesso a informação [...]". Segundo Paes (2004, p. 54-56) a tramitação passa pelas seguintes fases: 1 . Produção que seria a fase os arquivos correntes ou em curso constantemente pesquisado. 2. Protocolo adota as seguintes práticas: recebimento e classificação e registro e movimentação - o setor de protocolo funciona como ponto central de ordenamento de documentos.

Diante das exposições de Paes (2004) sobre protocolo, podemos concluir que o protocolo é uma unidade indispensável para a gestão de documentos nos órgãos e entidade, pois sua principal atividade é de atuar na produção, distribuição e controle dos documentos em curso, ou seja, documentação na primeira fase do ciclo de vida, sua principal função é de agilizar os processos. Em harmonia com a LEI 8.159/91, que considera a gestão de documentos um "conjunto de procedimentos e operações técnicas referentes à produção, tramitação, uso, avaliação e arquivamento em fase corrente e intermediária, visando a sua eliminação ou 
recolhimento para guarda permanente". O termo protocolo por sua vez comporta várias acepções como exemplifica Ferreira (2010, p. 619).

1. Registro de atos públicos; 2. Registro das audiências nos tribunais, ou duma conferência ou deliberação diplomática; 3 . Repartição onde se registra entrada de documentos; 4. Formulário regulador de atos públicos; 5. Acordo internacional; 6. Livro de registro de correspondência; 7. Conjunto de cerimônia; 8. Conjunto de regras e especificações técnicas que regulam a transmissão de dados entre computadores ou programas, permitindo a detecção e a correção de erros.

O protocolo é a unidade encarregada de junto ao órgão ou instituição de dar o suporte de recebimento e expedição de documentos. De acordo com o (ARQUIVO NACIONAL 2005) protocolo é "Serviço encarregado do recebimento, registro, classificação, distribuição, controle da tramitação e expedição de documentos".

\section{ARQUITETANDO OS DOCUMENTOS DE UM ARQUIVO DE ARQUITETURA}

Os Arquivos são compostos por documentos que são produzidos organicamente por uma instituição pública ou privada que precisam salvaguardar informações que foram produzidas e estruturadas por processos de trabalho que em sua essência são gerados como partes que se inter-relacionam com o todo em função de um objetivo em comum. Neste sentido, o arquivo de arquitetura é percebido como um conjunto de documentos produzidos com um propósito em comum, que neste caso seria a conclusão de uma edificação.

$\mathrm{O}$ arquivo arquitetônico é constituído por um processo complexo de produção. Com a evolução das técnicas de concepção tornou-se palpável a representação e visualização das características de um projeto para além da mente de seu criador, utilização de desenhos tridimensionais como forma de caracterização de projetos leva a um entendimento das características finais do produto, antes mesmo de ter um tijolo assentado.

No passado os documentos arquitetônicos possuíam grandes dimensões, eram imensas folhas de papel e se precisava de um espaço físico considerável para sua confecção, armazenamento e manutenção. Na atualidade os documentos passam por outro processo de confecção que demanda menos espaço físico que no passado, no entanto, sua concepção tornou-se mais complexa, seu tamanho é medido em $b^{l} t^{l}$ e isso os torna sem sombra de dúvidas um desafio para a arquivística contemporânea no que tange a organização e tratamento desses arquivos especiais e especializados.

Como destacaram Santos e Venâncio (2015), uma série de documentos distintos entre si compõe os arquivos de arquitetura que pode ser explorado e concebido, podemos citar na composição: plantas, fachadas, perspectivas manuais, croquis, esboços, fotografias, maquetes virtuais, maquetes físicas, como também os documentos em forma de texto (inventários, contratos, documentos técnicos). No entanto, esses arquivos surpreendem pelo número de documentos produzido nos mais diversos gêneros. A saber: textuais, cartográficos, iconográficos, oficiais, digitais etc.

No campo da Arquivística os Arquivos Arquitetônicos são considerados Arquivos Especiais e ao mesmo tempo Arquivos Especializados; Especiais por causa do suporte e especializados por fazerem parte de uma área especifica do conhecimento. Os arquivos especiais possuem características próprias que os distingue dos arquivos tradicionais em suporte de papel, esses arquivos são uma consequência da evolução técnica e tecnológica de concepção. $\mathrm{O}$ termo arquivo especial na literatura arquivística é usado genericamente para identificar os arquivos que tem sobre sua guarda documentos em diversos tipos de suporte. De acordo com Arquivo Nacional (2005, p.30) os arquivos especializados "como arquivo cujo acervo tem uma ou mais características comuns, como natureza, função ou atividade da entidade produtora, tipo, conteúdo, suporte ou data dos documentos, entre outros".

\footnotetext{
${ }^{1}$ Bit - unidade mínima de informação em um sistema digital, que pode assumir apenas 1 de 2 valores $(0 \mathrm{e} 1)$. (FERREIRA, 2010, p. 106).
} 
O termo "arquivos especiais" está diretamente relacionado com o suporte; entenda por suporte o objeto no qual são inscritas as informações. E o que seria informação? Segundo Capurro (2007, p.185) "a informação é um sub-produto[sic] da interpretação das atividades humanas, que por sua vez identificam e as registram nos mais variados tipos de documentos". Os tipos documentais originam-se das atividades, ela é o testemunho da produção documental que intercorrem a partir da organização interna, estrutural e funcional de cada organização, no arquivo de arquitetura, por exemplo, é composto na atualidade por diversos gêneros de documentos, que talvez por uma falta infortúnio a comunidade arquivística não tenha conseguido adentrar nesse arquivo e de um modo geral enfatizem como objeto que mereça tratamento arquivístico um único tipo/espécie de documentos, a planta. O tipo documental é uma característica que o documento assume de acordo com a atividade administrativa que o gerou. Conforme explica Bellotto (2006, p.57), "o tipo documental é a configuração que assume a espécie documental de acordo com a atividade que ela representa".

A existência de uma normatização dos tipos e espécie é a peça chave para uma boa gestão e para que isso torne algo palpável e eficiente; o arquivista será o responsável pela identificação e análise das características internas e externas do documento tendo com suporte as ferramentas fornecidas diplomáticas, nesse cenário ideal enfatizamos a importância da identificação das tipologias documentais. Duranti (1998, p.45) define "Diplomática como sendo uma disciplina que estuda, identifica e avalia as características do documento arquivística confrontando há todo tempo a relação orgânica dos documentos com seu produtor". Neste caso, constatamos que o documento de arquitetura é um todo orgânico que possui características especificas que o relacionam com seu produtor.

A tipologia dos documentos de arquitetura vem sofrendo sucessivas mudanças ao longo de sua evolução técnica, isso é uma consequência da adaptação do arquiteto frente ao avanço tecnológico, adequação a legislação, aumento da capacitação e desenvolvimento na formação profissional.

No campo da arquivologia os tipos/espécies documentais mais conhecidos produzidos em grandes formatos são mapas e plantas, no entanto pouco se sabe o a respeito da diferença tipológica deste documento arquivístico. De acordo com Simon e Tort (2007, p. 15-17) "os mapas seriam documentos gráficos contendo informações de um ponto geográfico de um determinado território e plantas como sendo um documento gráfico determinado a representar uma construção tridimensional construída ou idealizada". Além do pouco conhecimento arquivístico encontrado na literatura da área se assenta na discordância em relação ao uso do termo Arquivos de Arquitetura, onde a maioria dos autores só concorda com o uso do termo quando é usado para descrever Arquivos Pessoais.

Diante do exposto nos propomos neste trabalho a investigação mais aprofundada processos de trabalho em um escritório de arquitetura, mais precisamente no Escritório Vila Flor Arquitetura, de modo a investigar os tipos e espécies de documentos produzidos e tramitado como forma de encontrar e desvendar o ponto que uni e separa a arquivologia e a arquitetura áreas tão diferentes, mas que tem um ingrediente em comum: o Arquivo.

\section{A ORIGEM: ESCRITORIO VILA FLOR ARQUITETURA}

O escritório Vila Flor Arquitetura nasce de uma separação da anterior sociedade LTDA, o arquiteto fundador atua no mercado profissionalmente desde 2006, e a partir de 2014 passa a trabalhar de maneira solo explorando o próprio nome em um regime de eventuais parcerias com colaboradores e colegas.

A espinha dorsal econômica do escritório vem de clientes particulares dos mais diversos segmentos, a captação de clientes é dada por meio simples, onde a divulgação dos projetos e objetos construídos (obras) é o portfólio e principal veículo de propaganda, o usufruto do direito de propagação da imagem e congêneres é ponto decisivo para o andamento dessa atividade profissional.

O processo criativo faz parte da sequência de linha de raciocínio que cada arquiteto possui, essa forma de trabalho define o que na linguagem arquitetônica é denominada de "traço do arquiteto". Os produtos que são os 
desenhos de arquitetura e imagens eletrônicas tridimensionais são feitos em meio digital e entregues em suporte de papel.

Os arquitetos, assim como os artistas, sabem e reconhecem a materialidade específica do seu trabalho e de que este trabalho não pode ser descolado de um conjunto de relações sociais envolvidas na produção e outras determinações que se situam no contexto social mais amplo. Por outro lado, ao mesmo tempo em que seguem imperativos internos que direcionam sua criação e no que concebe como sendo os meios necessários para realizar um bom trabalho, têm que se defrontar com certas circunstâncias externas de prazos, especificações e exigências que dependem do caráter das demandas sociais. (KATO, 2012 p. 44).

O trabalho criativo se manifesta de forma individual, se atribuindo a tipificação, estética e estilo de cada profissional. Nesse sentido Kato (2012) o arquiteto é possuidor de um saber fazer que ultrapassem as barreiras do tempo, seu trabalho abarca recursos técnico e conhecimento que se desenvolve pela própria experiência do fazer. Viana (2015, p.137) também ressalta que "os arquivos de arquitetura podem servir de fonte para o estudo das ações dos indivíduos e instituições em determinado momento. Mesmo os documentos digitais e eletrônicos podendo ser servir como recursos ou objetos de prova e não por seu aspecto artística".

Um escritório de arquitetura pode ter em sua composição um arquiteto que neste caso poderia comprometer todo fluxo de trabalho, haja vista que ele teria que dominar todas as etapas do processo de concepção até a execução do projeto, o que pode trazer risco a obra o que comprometeria as outras etapas da produção devido ao volume de trabalho, sendo assim todo escritório independente do porte precisa dispor de colaboradores e parceiros internos ou externos que dê suporte a todo processo de concepção do projeto.

Todo o processo de gestão de projeto arquitetônico é uma jornada enfrentada pelo contratante e contratada; nascendo primordialmente do desejo de intervenção em

\footnotetext{
${ }^{2}$ RRT - Registro de Responsabilidade Técnica é o documento que comprova que projetos, obras ou serviços técnicos de Arquitetura e Urbanismo possuem um responsável devidamente habilitado e
}

espaço físico, esses são os primeiros sinais da natureza orgânica dessa atividade. O escritório Vila Flor desenvolve projetos para diversas cidades no Estado da Paraíba e percebe-se que cada cidade possui seu próprio trâmite.

Usamos como fonte de estudo o processo de tramitação da Prefeitura Municipal de João Pessoa - PMJP feito pela Secretaria de Planejamento - SEPLAN, que iremos exemplificar: se por acaso o arquiteto conseguir atender todas as recomendações e normas do código de urbanismo, código de posturas, código de obras, lei de uso e ocupação do solo, plano diretor da cidade de João Pessoa e o projeto legal chegar ao total de 4 pranchas; o cliente terá que levar 16 pranchas devidamente assinadas e carimbadas. Dando continuidade o profissional ainda tem que preencher manualmente 4 vias do Boletim de Classificação, 1 cópia da Inscrição Municipal do profissional, ou seja, o Imposto Sobre Serviço - (ISS), Registro de Responsabilidade Técnica em 4 cópias (RRT ${ }^{2}$ - CAU-PB) e por último uma cópia do projeto em formato digital enviada para o analista via E-mail e/ou gravada em um $\mathrm{cd}^{3}$.

Depois de todo processo de tramitação na prefeitura inicia-se uma nova etapa, que começa com a alteração e transformação do projeto legal em projeto executivo, constatamos que essa é uma das fases mais trabalhosas do processamento técnico, pois requer muita atenção e conhecimento das normas técnicas para sua elaboração, uma vez que é a partir do projeto executivo que se produz os projetos complementares e contabiliza-se financeiramente a edificação.

Toda documentação produzida no escritório, podemos reconhecer como sendo documento de arquivo. A formação de um arquivo é a prova da existência de uma instituição, e é através da produção de documentos que ela vai refletir suas atividades, uma vez que representam um conhecimento único de suas funções, uma vez que, todo processo de produção do arquivo de arquitetura são ritos próprios do labor do arquiteto que produz os mais diversos tipos/espécies de documentos nos mais diversos suportes.

com situação regular perante o Conselho para realizar tais atividades.

${ }^{3}$ Entenda por CD (discos compactos) suporte de armazenamento. 
Quadro 1 - Principais espécies identificadas.

\begin{tabular}{|l|l|l|}
\hline Programa de necessidades & Projeto de cobertura & Estimativa de custo \\
\hline Estudo preliminar & Projeto de ambientação & Estudo de viabilidade \\
\hline Anteprojeto & Planta de locação & Impostos \\
\hline Orçamento & Mapa (overlay) & Memorial descritivo \\
\hline Financeiro & Fachada & ISS \\
\hline Projeto Legal & Cortes & RRT \\
\hline Projeto Executivo & Vistas & Plano diretor \\
\hline Imagem 3D & Fotografias e Portfolio & \\
\hline Croquis & As Built & \\
\hline
\end{tabular}

Fonte: Escritório Vila Flor Arquitetura.

Neste ambiente o Projeto As built ${ }^{4}$ seria a correção do projeto executivo depois da obra finalizada, essa seria a versão final do projeto que deveria ser guardada pelo escritório, cliente e prefeitura, no entanto, esse projeto faz parte do conjunto dos projetos complementares, por tanto, teria que ter sido acordado antes pelo cliente e arquiteto, pois envolve custos. Contudo, segundo o Código de Ética e Disciplina para Arquitetos e Urbanistas - $\mathrm{O}$ arquiteto e urbanista deve, em concurso com o CAU, empenhar-se na preservação da documentação de projetos, obras e outros serviços de Arquitetura e Urbanismo, visando garantir o acesso da sociedade e das novas gerações de profissionais à história da profissão, essa guarda nos escritórios ocorre de forma bastante particular por se tratar de um "arquivo pessoal", pois seu produtor só se preocupa de preservar aqueles que talvez possa ser usado em um portfólio, não levando em consideração que seu trabalho pode ser rica fonte de pesquisa para as futuras gerações.

Nesse contexto o CAU funciona apenas como cartório, porquanto não é enviado nenhum arquivo com qualquer etapa do processo de concepção do projeto, apenas o preenchimento de identificação das partes e da edificação de forma muito geral na RRT. Talvez seja um dos motivos pela qual nenhuma prefeitura cobre esse projeto.

Outro item relegado é o Memorial Descritivo do Projeto Arquitetônico. Por não haver exigência legal, esse documento é negligenciado na maioria dos casos, principalmente quando envolvem clientes particulares. No escritório em análise tal documento é gerado apenas quando: há a exigências em contrato; quando é feito projetos arquitetônicos de estabelecimentos de saúde (clínicas, hospitais, centros médicos, laboratórios); projetos de locais de refeição (restaurantes, lanchonetes, bares); pois nesses casos há a exigência do órgão fiscalizador vinculado a prefeitura, chamado Vigilância Sanitária.

\subsection{ANÁLISE E PROPOSTA DO PROJETO COMO UM PROCESSO}

O Projeto é o principal objeto e o mais genérico entre as atividades de um arquiteto, ele reproduz através do desenho, recurso imaginário, em algo concreto, palpável como lajes, escadas, rampas, paredes, esquadrias e outros elementos. "O que assegura a excelência do processo de concepção de um projeto é o empenho de vários profissionais das mais diversas especialidades com inúmeros conhecimentos e técnicas, os quais possam participar do processo como cliente uns dos outros", Bertezini (2006, p.19).

$\mathrm{O}$ arquiteto é um profissional com a capacidade e competência para fazer as mudanças de melhoria de uma planta, isto significa que ele tem a competência para acompanhar todas as fases, pois o projeto passa por um ciclo de vida que precisa ser acompanhado desde a concepção até os últimos ajustes no final da obra. De acordo

\footnotetext{
${ }^{4}$ Projeto As Built regulado pela ABNT - NBR 14645-1 Elaboração do "como construído" (as built) para edificação.
} 
com Bertezini (2006) o projeto passa pelas seguintes fases:

\author{
Estudo Preliminar - EP; \\ Anteprojeto - AP; \\ Projeto Legal - PL; \\ Projeto Básico - PB; \\ Projeto Executivo - PE e \\ Projeto para Produção - PP.
}

De acordo com a NBR $13532^{5}$ as etapas técnicas para a elaboração de um projeto são as seguintes: Levantamento de dados; Programa de necessidade; Estudo de viabilidade; Estudo preliminar; Anteprojeto ou Pré-execução; Projeto legal; Projeto básico e Projeto para execução. De acordo com a referida ABNT cada fase do processo de concepção gera uma gama de documentos que se subdivide entre desenho, textos, fotografias e planilhas como discriminado a seguir.

Neste contexto de produção após a revisão da literatura aliado a análise dos dados conseguimos traduzir, através de simples fluxo informacional, $\mathrm{o}$ passo a passo do desenvolvimento de um Arquivo Arquitetônico, como demonstraremos na figura 12.

Figura 1 - Ilustração das figuras usadas na construção do processo.

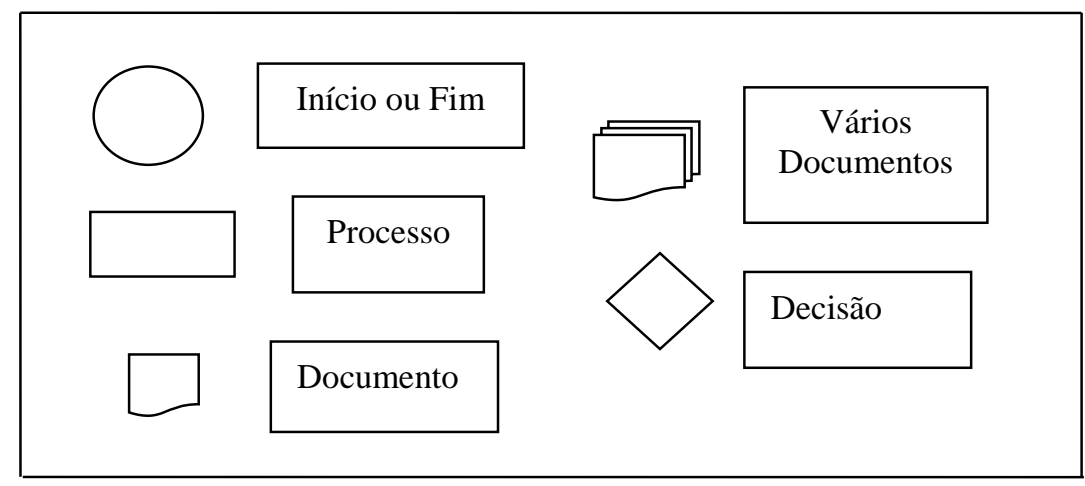

Fonte: Própria.

\footnotetext{
${ }^{5}$ NBR 13.532 /1995 - Elaboração de projetos de
} edificações - Arquitetura. 
Figura 2: Proposta de Fluxo informacional.



Fonte: Própria. 
A relação entre arquiteto e órgãos reguladores em um primeiro momento pode ser visto como algo expressivamente comercial, pois a sua atuação profissional está ligada a administração pública de um modo geral, a pagamentos de impostos. Toda relação que envolve o ofício de arquiteto demanda muito conhecimento técnico, legal, material e tecnológico. Por essa razão merece uma atenção especial, a arquitetura é algo que faz parte da vida das pessoas, ela modifica a paisagem, os ambientes e interfere diretamente na vida das pessoas, o que compreendemos que a vinculação aos órgãos de controle e fiscalização seja intrínseca da gestão de um escritório, pois é preciso que se compreendam as normatizações de cada entidade que normalizam as especificações técnicas de cada tipo de edificação.

Essa foi a forma que o poder público encontrou de barrar e minimizar os possíveis danos que uma edificação mal concebida e executada possa fazer a uma determinada comunidade a exemplo podemos citar: a lei orgânica municipal; Estatuto da cidade; Código Urbano; Decreto 5844/2007 Usos do solo do município de João Pessoa e muitas outras normas que vigoram a esse respeito das três esferas de poder, portanto percebemos a importância compartilhar como ocorre na prática essas relações através do fluxograma a seguir.

Figura 3: Fluxograma que existe entre os órgãos de controle e fiscalização e o escritório de arquitetura.



Fonte: Própria.

\subsection{PROTOCOLO E ACOMPANHAMENTO DO PROCESSO JUNTO A PMJP}

A Prefeitura Municipal de João Pessoa criou a Secretaria de Planejamento - SEPLAN. Esta secretaria tem a competência de articular, produzir e fomentar as políticas públicas nas áreas de planejamento e orçamento do município e como uma estratégia para o desenvolvimento desse trabalho, citaremos algumas atribuições da SEPLAN na área de planejamento. Entre as responsabilidades da secretaria estão o controle e planejamento urbano; parcelamento, uso, e ocupação de solo urbano; aprovação e fiscalização de obras entre outras. Na cidade de João Pessoa, existe uma sequência de pessoas envolvidas na secretaria e no protocolo, que são os analistas.

Os tipos/espécies de documentos diferemse conforme a disposição de cada personagem no processo de concepção do projeto; os documentos produzidos e entregues na via arquiteto-cliente pertencem a um conjunto específico que só dizem respeito a esses dois agentes, bem como nas outras possíveis relações, por exemplo: arquiteto-órgão competente; cliente-órgão competente.

É importante mencionar que existe uma tríplice relação: arquiteto, cliente e órgãos competentes. As relações entre estas três partes, geram documentos peculiares que 
variam de acordo com cada contrato estabelecido entre as partes. No que tange esses documentos e sua sequência, em sua maioria o roteiro é o mesmo, a saber: desejo do cliente; busca do arquiteto pelo cliente; primeiros estudos realizados pelo arquiteto; alterações de projeto; aprovação do projeto pelo cliente; encaminhamento do projeto, em quatro vias, ao órgão competente; aprovação do projeto pelo órgão; devolução de uma das cópias com as devidas autorizações ao cliente; início da obra objeto do projeto.

Durante o período de observação podemos notar que no protocolo da Prefeitura Municipal de João Pessoa as pessoas que se dirigiam SEPLAN para dar entrada em processo apresentam uma gama de documentos que são exigidas pela Prefeitura Municipal de João Pessoa - PMJP, que poderá ser conferido no site da PMJP ou nos anexos deste trabalho, na pesquisa conseguimos identificar conforme listagem a seguir.

Principais tipos/espécies documentais observados e identificados na relação Cliente, Escritório e Prefeitura Municipal de João Pessoa.

- Cópia da Inscrição Municipal do profissional, (Imposto Sobre Serviço - ISS)

- Registro de Responsabilidade Técnica (RRT - CAU-PB)

- Boletim de Classificação

- Mínimo de 4 pranchas do Projeto Legal

- $\quad$ Arquivo digital enviado por E-mail

- Formulário de requerimento da SEPLAN

- Certidão de registro imobiliário atualizado

- Aprovação e carimbo do corpo de bombeiros

- Aprovação da vigilância sanitária

- Levantamento topográfico

- $\mathrm{RG}$ e CPF do proprietário

$\mathrm{Na}$ entrada do documento na instituição deve ocorrer na unidade de protocolo da repartição, ambiente necessário para que se inicie o processo, que abrangem as operações de recebimento, classificação, registro, distribuição, tramitação e expedição.

No setor de análise da (SEPLAN) os documentos solicitados são entregues no setor de protocolo do órgão pelo o requerente
(Arquiteto, construtor, cliente), que preenchem uma guia de requerimento de entrada de análise de projeto, esse processamento pode demorar de 30 a 45 dias dependendo do volume de requerimento e da análise do arquiteto-analista da prefeitura, responsável por cada processo. Ao apresentar a documentação, o requerente recebe um documento com a numeração do processo, que deveria ser o canal de comunicação entre o impetrante e prefeitura, no entanto, os analistas informam que por terem muitos processos tramitando no setor será melhor que o interessado volte pessoalmente dentro de 15 a 20 dias para saber em qual fase da análise o processo se encontra. Essa praxe mostra que mesmo com todo aparato tecnológico e legal o setor de analise apresenta falhas, desatualização nos dados e a sobrecarga das atividades de análise.

Outra realidade mais dura é a que encontramos na maioria das cidades do interior, observamos quando os projetos do Escritório Vila Flor Arquitetura são desenvolvidos para clientes que residem em municípios de pequeno porte, onde as prefeituras locais não possuem órgão ou setor responsável de planejamento urbano, sendo assim mais frágeis nesses assuntos que tangem tramitação de projetos arquitetônicos. A tramitação ocorre de maneira mais simplória nessas pequenas cidades, a exigência se resume a: uma cópia da RRT do profissional em exercício e apenas 01 (uma) via do item Planta Baixa; os demais documentos que são comumente exigidos em cidades de maior porte e capitais, não se aplicam a extensa maioria das prefeituras no interior do nosso Estado, por exemplo.

De acordo com o que foi supracitado, existem subjetividades: discrepância com os documentos que são exigidos legalmente pela Prefeitura e os que são exigidos oficiosamente pelos Analistas, a respeito de cópia do arquivo digital em formato dwg (AutoCad) em CDROM ou via e-mail. Outro ponto é a falta de padronização dos pareceres técnicos, ora são confeccionados documentos com timbre da Prefeitura, com os itens que precisam ser corrigidos, ora as observações são manuscritas a lápis grafite na própria prancha, e são encaminhadas informalmente aos requerentes do projeto para correção, pois em alguns casos a especificação de uma analista não é a mesma 
em um mesmo objeto analisado, o que corrobora para a subjetividade do trabalho. A mesma lógica segue quanto a qual funcionário irá fazer a análise do projeto arquitetônico, podendo divergir: no tempo da análise e na exigência da mesma. O objeto elaborado pelo arquiteto, chamado Projeto Arquitetônico, percorre um caminho e um tramite especifico junto as Prefeituras Municipais que implica na produção e comprovação de vários documentos.

\section{CONSIDERAÇÕES FINAIS}

A pesquisa contribui ao inovar na realização, em João Pessoa, em um estudo científico de natureza qualitativa sobre a produção e tramitação dos documentos arquitetônico. Proporcionando alguns avanços teóricos, na medida em que se pode identificar as fases do processo de produção de um projeto arquitetônico em todas as variantes.

Sem dúvida o ineditismo desse trabalho se assenta, no levantamento detalhado de produção e tramitação dos documentos de Arquitetura ampliando, mesmo que timidamente o conhecimento acerca dos Arquivos Especiais e Especializados para a Arquivologia. Assim, as plantas ou mapas, termo usado pela arquivística, mostrou-se representar apenas uma pequena parcela conhecida dos muitos tipos e espécies de documentos produzidos e tramitados pela arquitetura de um modo geral, revelando-se ser apenas um estudo introdutório a respeito desses arquivos.

Identificou-se também os problemas de tramitação e uma falta de normatização nacional sobre este processo no que tange os documentos de arquitetura, principalmente em relação à legislação e órgãos reguladores que não possuem um manual nem uma recomendação que direcione os que produzem e que lidam direta ou indiretamente com esse tipo de documento.

É preciso explorar cada vez mais essa temática, visto que percebemos nessa pesquisa que a arquivística não possuem o conhecimento a respeito sobre a metodologia de trabalho não só dos arquitetos, mas de muitos outros profissionais que trabalham com os mais variados tipos e espécie de documentos produzidos e tramitados dentro e fora dos escritórios bem como são identificados, armazenamentos e tratamentos, de modo que aja uma unidade em todos os processos.

Contudo, é necessário admitir que faça parte da função do arquiteto elaborar projetos e que o retrabalho é uma consequência dessa atividade por esta razão compreendemos a importância da criação de um modelo de gestão de documentos específico que possam ser lidos e compreendidos por aqueles que empiricamente desenvolvem algum tipo de atividade dentro desses arquivos.

Artigo recebido em: 05/04/2017

Aceitação definitiva em: 19/10/2017

\title{
IDENTIFICATION OF DOCUMENTARY TYPOLOGY AS A METHODOLOGY FOR ORGANIZING ARCHITECTURE ARCHIVES
}

\begin{abstract}
This research aims to present the particularities that occur in the production and processing of architecture documents in order to promote a detailed knowledge about the processes of formation of this type of archives. It addresses the issue of document management with regard to the identification of types and species of documents, production and processing in an architecture office, understanding in the archival context - Special and Specialized
\end{abstract}


Archives, as well as the appreciation of the inspection and control bodies through the guidelines, manuals, norms or recommendations that direct the architect and the archivist in the process of organization this documentation. Bringing as a repercussion the demonstration of the flowchart between the control / inspection bodies and the architecture offices, contemplating all stages of production and processing of architecture documents in the office environment and outside it. Thus, throughout this research we could identify the lack of a manual, guideline or norms that directs archivists and other professionals who deal with these types and species of document how to manage these arquives.

Keywords: Archives of Architecture. Specialized and Special Arquives. Production and documentary processing.

\section{REFERÊNCIAS}

Arquivo Nacional (Brasil). Dicionário Brasileiro de Terminologia Arquivística. Rio de Janeiro: Arquivo Nacional, 2005. Disponível em:

$<$

http://www.conarq.arquivonacional.gov.br/im ages/publicacoes textos/dicionrio de termin ologia_arquivistica.pdf >. Acesso em: 08 mar. 2017.

BERNARDES, Ieda Pimenta; DELATORRE, Hilda. Gestão Documental Aplicada. São Paulo: Arquivo público de São Paulo, 2008. Disponível <http://amormino.com.br/livros/00000000gestao-documental-aplicada.pdf $>$. Acesso em: 10 fev. 2017.

BELLOTTO, Heloísa Liberalli. Diplomática e tipologia documental em arquivos. $2^{\circ}$ EdBrasília: Briquet de Lemos, 2008.

BERTEZINI, A. L. Métodos de avaliação do processo de projeto de arquitetura na construção de edifícios sob a ótica da gestão da qualidade. 193f. Dissertação (Mestrado em Engenharia) - Departamento de Engenharia de Construção Civil, Universidade de São Paulo. São Paulo, 2006. Disponível em: <http://www.infohab.org.br/>. Acesso em: 10 fev. 2017.

BRASIL. Lei $\mathrm{N}^{\circ} 8.159$ de 8 de janeiro de 1991. Dispõe sobre a política nacional de arquivos públicos e privados e dá outras providências. Brasília, $170^{\circ}$ da Independência e $103^{\circ}$ da República. Disponível em: <http://www.planalto.gov.br/ccivil 03/leis/L8 159.htm>. Acesso em: 08 mar. 2017.
CAPURRO, Rafael; Hjorland, Birger. O Conceito de Informação. Ana Maria Pereira Cardoso (Trad.), Maria da Glória Achtschin Ferreira (trad.), Marco Antônio de Azevedo (Trad.) Perspectivas em ciência da informação, v.12, n.1, p. 148-207, jan./abr.2007).

<http://bogliolo.eci.ufmg.br/downloads/CAP URRO.pdf>. Acesso em: 27 set. 2016.

DURANTI, Luciana. Diplomatics: new uses for na old science. Society of American Archivists: Maryland, 1998.

FERREIRA, Aurélio Buarque de Holanda. Mini Aurélio: o dicionário da língua portuguesa. 8. ed. - Curitiba: Positivo, 2010.

KATO, Volia Regina Costa. Notas reflexões sobre o fazer arquitetônico. 2012. 243f. Tese (Doutorado em Arquitetura e Urbanismo) Universidade Presbiteriana Mackenzie, São Paulo, 2012, p. 32. Disponível em: $<$ http://tede.mackenzie.com.br/tde_busca/arq uivo.php?codArquivo=2668 $>$. Acesso em: 06 fev. 2017.

PAES, Marilena Leite. Arquivo: teoria e prática. $3^{\mathrm{a}}$ ed. Ver. Ampl. Rio de Janeiro: Editora FGV, 2004.

SANTOS, Silvana; VENÂNCIO, Renato. Arquivos institucionais e memória da UFMG: um estudo dos arquivos de arquitetura. $4^{\circ}$ seminário Ibero-americano, Arquitetura e documentação, Belo Horizonte, 2015. P, 3-5. Disponível em: < http://www.forumpatrimonio.com.br/arqdoc2 015/artigos/pdf/113.pdf >.Acesso: 20 fev. 2017. 
Relatos de Experiência

SIMON, Andreu Carrascal; TORT, Rosa Maria Gil. Los documentos de arquitectura y cartografia: qué son y cómo se tratan. Espanã: Ediciones Trea, 2007.
VIANA, Claudio Muniz. Da concepção ao projeto de execução: a gênese documental dos arquivos de arquitetura Ponto de Acesso, Salvador, v.9, n.2, p. 123-155, jan. 2017. 